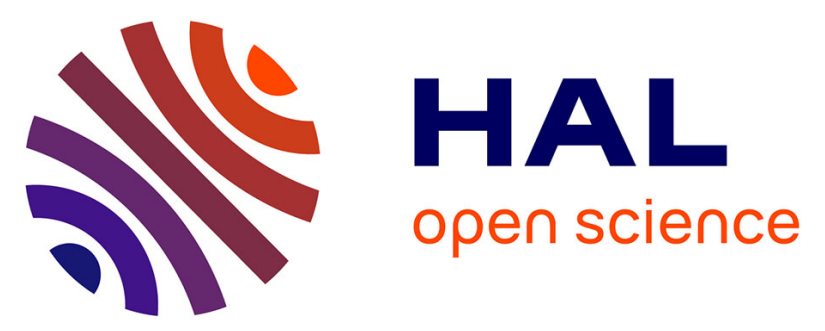

\title{
Quantification of the transport of chemical constituents from the polar vortex to midlatitudes in the lower stratosphere using the high-resolution advection model MIMOSA and effective diffusivity
}

Alain Hauchecorne, Sophie Godin, Marion Marchand, Birgit Heese, Claude Souprayen

\section{To cite this version:}

Alain Hauchecorne, Sophie Godin, Marion Marchand, Birgit Heese, Claude Souprayen. Quantification of the transport of chemical constituents from the polar vortex to midlatitudes in the lower stratosphere using the high-resolution advection model MIMOSA and effective diffusivity. Journal of Geophysical Research: Atmospheres, 2002, 107 (D20), pp.SOL 32-1-SOL 32-13. 10.1029/2001JD000491 . insu03104938

\section{HAL Id: insu-03104938 \\ https://hal-insu.archives-ouvertes.fr/insu-03104938}

Submitted on 10 Jan 2021

HAL is a multi-disciplinary open access archive for the deposit and dissemination of scientific research documents, whether they are published or not. The documents may come from teaching and research institutions in France or abroad, or from public or private research centers.
L'archive ouverte pluridisciplinaire $\mathbf{H A L}$, est destinée au dépôt et à la diffusion de documents scientifiques de niveau recherche, publiés ou non, émanant des établissements d'enseignement et de recherche français ou étrangers, des laboratoires publics ou privés. 


\title{
Quantification of the transport of chemical constituents from the polar vortex to midlatitudes in the lower stratosphere using the high-resolution advection model MIMOSA and effective diffusivity
}

\author{
Alain Hauchecorne, Sophie Godin, Marion Marchand, Birgit Heese, and Claude Souprayen \\ Service d'Aéronomie du CNRS, Verrières-le-Buisson Cedex, France
}

Received 8 February 2001; revised 9 June 2001; accepted 18 June 2001; published 15 October 2002.

[1] The observed decrease of ozone in the northern midlatitude lower stratosphere is only partially reproduced by chemical models. The transport of ozone-depleted air from the polar vortex is one of the proposed mechanisms to explain the discrepancy. Here we present a study on the quantification of the air mass transported from the polar vortex to midlatitude during the four winters 1996-1997 to 1999-2000, in relation with vortex filamentation and break up, using the high-resolution advection model MIMOSA on isentropic surfaces. Sensitivity tests show that the advection model is able to predict the location of polar filaments with accuracy better than $100 \mathrm{~km}$, limited by uncertainties in meteorological advecting wind fields. The effective diffusivity diagnostic is used to evaluate the intensity of the vortex edge barrier and to quantify the transport of air from the polar vortex to midlatitude. The intensity of the polar barrier is increasing with height from 400 to $550 \mathrm{~K}$ and is nearly constant above. During periods with a cold and undisturbed vortex, favorable to chlorine activation, the transport is very weak. This suggests that the midwinter vortex filamentation plays a minor role in the midlatitude ozone decline. In the opposite limit, during a stratospheric warming up to $30 \%$ of the polar vortex air is transported to midlatitudes. The cumulative transport from early January to end of April across the polar edge varies from almost $5 \%$ of the polar vortex air at $675 \mathrm{~K}$ in 1997 to $50 \%$ at $435 \mathrm{~K}$ in 1999. INDEX TERMS: 0341 Atmospheric Composition and Structure: Middle atmosphere-constituent transport and chemistry (3334); 3334 Meteorology and Atmospheric Dynamics: Middle atmosphere dynamics (0341, 0342); 3337 Meteorology and Atmospheric Dynamics: Numerical modeling and data assimilation; KEYWORDS: stratosphere, ozone, transport, model, vortex, filament

Citation: Hauchecorne, A., S. Godin, M. Marchand, B. Hesse, and C. Souprayen, Quantification of the transport of chemical constituents from the polar vortex to midlatitudes in the lower stratosphere using the high-resolution advection model MIMOSA and effective diffusivity, J. Geophys. Res., 107(D20), 8289, doi:10.1029/2001JD000491, 2002.

\section{Introduction}

[2] The decrease of total ozone at Northern Hemisphere midlatitudes is now well recognized [World Meteorological Organization $(W M O), 1999]$. It is much larger in winter/ spring (about $4 \%$ per decade) than in summer/autumn $(2 \%$ per decade). The observed decrease occurs mainly in the lower stratosphere. Until today, the origin of this decrease is an open and controversial question. Several chemical and dynamical mechanisms have been proposed, among them the in situ activation of halogen species by heterogeneous chemistry on sulfuric acid aerosols, changes in the intensity of the Brewer-Dobson circulation which control the diabatic descent at middle and high latitudes, and the transport from the polar vortex of air depleted in ozone due to the vortex erosion and break up. The goal of this paper is to evaluate the

Copyright 2002 by the American Geophysical Union. 0148-0227/02/2001JD000491 importance of the last proposed mechanism with the help of a high-resolution transport model.

[3] Fine-scale layering in lower stratospheric ozone profiles has long been recognized. Analysis of the world-wide network of ozonesondes has allowed Reid and Vaughan [1991] to show that layers typically one kilometer thick, either depleted or enriched in ozone, appear preferably in winter and spring in the extratropics, between 12 and $18 \mathrm{~km}$. These authors linked occurrences of such ozone layers, or laminae, to transport across jet streams, and at high latitudes in particular, to the presence and break up of the winter polar vortex. Reid and Vaughan [1991] revealed the important role of filaments in the vortex erosion process. There is a clear coincidence of the altitude range with the highest ozone decrease rates and the range with the highest number of ozone filaments observed $(13-19 \mathrm{~km})$. The mixing across the vortex edge can also lead to intrusions of midlatitude air into the lower stratospheric Arctic vortex [Plumb et al., 1994]. Exchange 
and mixing between vortex and extra-vortex air masses via laminae/filaments can have various effects:

1. Transport of chemically prepared vortex air from the polar night region to sunlit midlatitudes resulting in ozone destruction here; this process can take place in midwinter.

2. Transport of already ozone-depleted vortex air to midlatitudes contributing to the observed loss of ozone there.

3. Transport of ozone poor air from the middle and low latitudes lower stratosphere to high latitudes and intrusion into the vortex, and transport of ozone rich air from the high-latitude lower stratosphere to midlatitudes; these processes cause natural variations of middle and high latitude total ozone.

[4] Polar filaments are generated by deformations of the polar vortex edge induced by planetary Rossby waves [McIntyre and Palmer, 1984]. Filaments are stretched by the meridional gradient of zonal wind at the south part of the polar jet. Mechanisms of formation are linked with the large-scale structure of the horizontal wind field and are well represented in meteorological analysis models even with a relatively coarse resolution (i.e. T42 in spherical harmonics, equivalent to $2.5^{\circ} \times 2.5^{\circ}$ horizontal resolution) as demonstrated by Methven and Hoskins [1999] and Weaver et al. [2000]. Dissipation and mixing of polar filaments with surrounding midlatitude air occur when their width is too small to be captured by meteorological models. Though the production of filaments of tracers is strongly related to planetary waves disturbances at the vortex edge, the successive reduction in scale of such filaments has to be halted ultimately by smaller-scale processes leading to molecular mixing. Among those are the cumulative (along the trajectory of the filaments) effect of breaking inertia-gravity waves. The redistribution in latitude of polar air transported by filaments depends on those mechanisms. The intensity and the nature of the mix-down of filaments (in the final steps) may have also an impact on the ozone loss in the Arctic vortex as suggested by Edouard et al. [1996] for winter 19941995 using a very high-resolution model with a simplified chemistry. However, this result is questioned by Searle et al. [1998a, 1998b] who found for the same winter a very small dependency of ozone loss on model resolution and Sparling et al. [1998], who estimated that the effect of model resolution was limited to the vortex edge. A possible effect of small-scale filamentary structures on the deactivation of chlorine at the edge and outside the vortex is also discussed by Tan et al. [1998].

[5] Several previous studies have shown that high-resolution transport models [Orsolini, 1995; Orsolini et al., 1997] or contour advection with surgery (CAS) [Waugh et al., 1994; Mariotti et al., 1997] can represent the observed filaments down to scales much smaller than the scales resolved in the advecting wind field. For instance, in the case of tropospheric baroclinic eddies, Methven and Hoskins [1999] showed that the ratio between the smaller scale resolved in the wind field and the size of the smaller scale reproduced in the tracer field is at least 6. Manney et al. [1998] obtained an improvement in the reproduction of lidar and balloon ozone profiles, using data provided by the Upper Atmospheric Research Satellite (UARS) Microwave Limb Sounder (MLS), when they applied a high-resolution reverse trajectory technique initialized with the satellite data. Orsolini et al. [1998] reproduced the lamination observed in midlatitude balloon profiles of long-lived stratospheric species using reverse domain filling trajectories initialized with UARS data.

[6] Here we present an estimation of the transport from the polar vortex to midlatitudes during winters 1996-1997 to 1999-2000 using a high-resolution model of the isentropic advection of a passive tracer and the effective diffusivity diagnostic developed by Nakamura [1996]. The advection model MIMOSA is described in section 2. Section 3 presents a sensitivity study on the accuracy of the location of filaments simulated by the advection model. The effective diffusivity is used in section 4 to evaluate the intensity of the polar barrier and in section 5 to quantify the transport from the polar vortex to midlatitude. A summary of the results is given in section 6 .

\section{Model Description}

[7] The Modélisation Isentrope du transport Mésoéchelle de l'Ozone Stratosphérique par Advection (MIMOSA) high-resolution advection model of potential vorticity (PV) has been developed at Service d'Aéronomie in the frame of the European Union project Meridional Transport of Ozone in the Lower Stratosphere (METRO), which was part of Third European Stratospheric Experiment on Ozone (THESEO) 2000 campaign. The model was used to interpret the observations of ozone laminae in lidar profiles, especially at Observatoire de Haute-Provence (OHP, $44^{\circ} \mathrm{N}$, $5.7^{\circ} \mathrm{E}$ ), and to support the planning of an airborne ozone lidar [Heese et al., 2001] on board of a French Falcon (Mystère 20). The basic assumption is that PV and ozone mixing ratio are very well correlated on an isentropic surface and the location of ozone filaments can be visualized using PV as a quasi-passive tracer.

[8] The model runs on an isentropic surface, starting on an orthogonal grid in an azimuthal equidistant projection centered at North Pole (parallels are represented as concentric equidistant circles) It covers latitudes between $10^{\circ} \mathrm{S}$ and $90^{\circ} \mathrm{N}$ in the present version. The size of an elementary grid cell is either $37 \times 37 \mathrm{~km}$ (three grid points/degree of latitude) or $18.5 \times 18.5 \mathrm{~km}$ (six grid points/degree) Meteorological data are taken from six hourly European Center for Medium-Range Weather Forecast (ECMWF) analysis at $1.125^{\circ}$ latitude and longitude resolution, corresponding to the T106 truncation. They are provided by the THESEO database set up at the Norwegian Institute for Air Research (NILU). Data are first interpolated at isentropic levels and on the fine MIMOSA grid. PV fields are either extracted from the database or computed internally.

\subsection{Advection and Regridding}

[9] The model starts from the ECMWF PV field interpolated on the MIMOSA orthogonal grid. The PV of each grid point is advected using ECMWF winds. We have to keep in mind that the quantity advected by the model is not the true dynamical PV but a "quasi-passive PV" which correlates well with the concentration of ozone or others long-lived trace species in the lower stratosphere. In particular, the true PV is probably poorly conserved in small-scale filaments due to radiative and dynamical processes. In order to avoid confusion, we will call the quantity advected by MIMOSA 


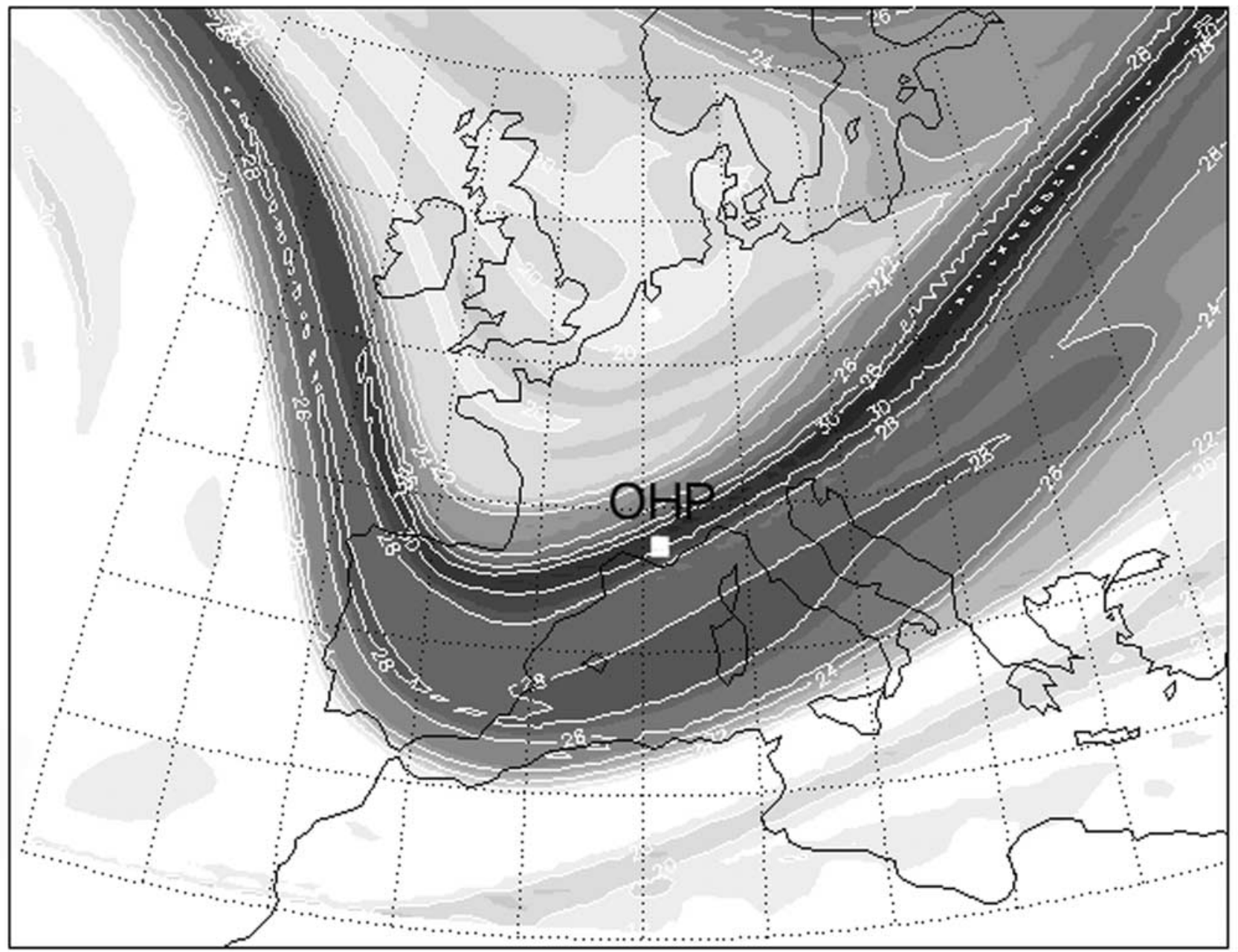

Figure 1. Map of advected PV on 5 December at 0000 UT at $460 \mathrm{~K}$. The location of OHP station is shown. PV is units $10^{-6} \mathrm{Km}^{2} \mathrm{~kg}^{-1} \mathrm{~s}^{-1}$.

"advected potential vorticity" (APV) in the continuation of the paper.

[10] If we consider a square formed by four adjacent grid points at the initial time, this square is stretched and deformed by horizontal gradients in the wind field. After a given time, it is necessary to reinterpolate the APV field to the original grid in order to keep the distance between two adjacent points approximatively constant. A time interval of six hours has been chosen between two successive regriddings. For this time interval, the average change of the distance between two adjacent grid points ranges from 10 to $15 \%$ in the region between 400 and 675 $\mathrm{K}$ potential temperature. The regridding process produces a numerical diffusion as explained in Appendix A. If a bilinear interpolation is used, the equivalent numerical diffusivity is equal to $5280 \mathrm{~m}^{2} \mathrm{~s}^{-1}$ for the nominal horizontal resolution $\Delta x=37 \mathrm{~km}$. In order to minimize the numerical diffusion, an interpolation scheme, based on the preservation of the second-order momentum of a PV perturbation, has been implemented. It limits the effect of numerical diffusivity to $1350 \mathrm{~m}^{2} \mathrm{~s}^{-1}$ (Appendix A). This value is close to the value of $1000 \mathrm{~m}^{2} \mathrm{~s}^{-1}$ estimated by Waugh et al. [1997] by tracer-tracer scatterplots from aircraft data or to the upper limit deduced from the vertical diffusion $0.01 \mathrm{~m}^{2} \mathrm{~s}^{-1}$ obtained by Balluch and Haynes [1997] using aircraft data and an aspect ratio 300 between horizontal and vertical structures $\left(k_{x x}=0.01 \times\right.$ $300^{2}=900 \mathrm{~m}^{2} \mathrm{~s}^{-1}$ ).

\subsection{Relaxation}

[11] In the lower stratosphere, PV is assumed to be conserved on isentropic surfaces for periods of one to two weeks [Orsolini, 1995]. This is particularly well verified at levels $475 \mathrm{~K}$ and below where the diabatic cooling of the potential temperature in the winter polar vortex is less than $1 \mathrm{~K} /$ day [Knudsen and Carver, 1994]. For periods longer than two weeks, the diabatic transport across isentropic surfaces due to radiative cooling and warming of air as well as the diabatic advection term in the PV equation have to be taken into account. See Haynes and McIntyre [1990] for further discussion on PV conservation. The information on diabatic changes in the PV field, at least for larger scales, can be extracted from ECMWF fields. In MIMOSA this is made by applying to the APV field a relaxation toward the ECMWF PV field with a time constant of 10 days. In order to preserve the filamentation structure, the relaxation term is only applied to scales larger than $300 \mathrm{~km}$. To do that, both MIMOSA and 


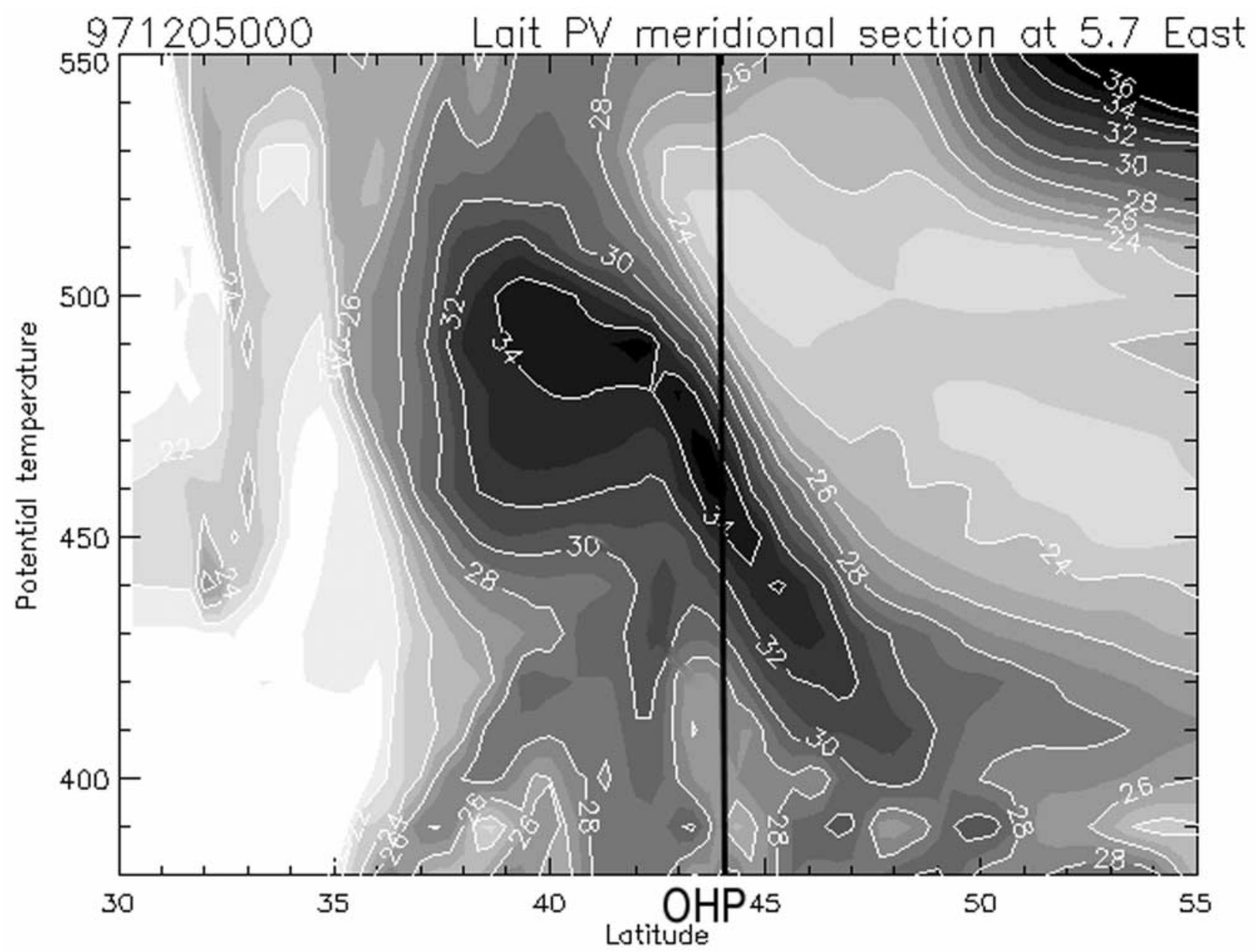

Figure 2. Latitude-potential temperature cross section of MIMOSA advected PV, corrected for vertical dependence on the increasing potential temperature with altitude [Lait, 1996], on 5 December 1997 at $0000 \mathrm{UT}$ at the longitude of OHP station. The latitude of OHP is $43.9^{\circ} \mathrm{N}$. The reference level for Lait PV correction is $475 \mathrm{~K}$. PV is in units $10^{-6} \mathrm{Km}^{2} \mathrm{~kg}^{-1} \mathrm{~s}^{-1}$.

ECMWF fields are smoothed to the same resolution and the difference between the two fields is used to compute the relaxation term. Using this procedure, it is possible to run continuously the model and to follow the evolution of filaments during several months, for instance from November to April for the study of the filamentation and the final break up of the Arctic vortex.

\subsection{THESEO-THESEO 2000 Campaigns}

[12] During the three winters of THESEO and SOLVETHESEO 2000 campaigns, 1997/1998 to 1999/2000, the model ran in real time for measurement alerts to be sent to the ground-based network of ozone lidar and to ozonesonde stations and for the planning of airborne lidar flights. The model started on 1 November and ran continuously until the end of April. Five-day forecasts of ECMWF winds were used to create predicted maps of filaments accessible in real time on the Web for the participants to the campaign.

\section{Sensitivity Tests}

[13] At the beginning of December 1997, a large filament developed above Western Europe and the ozone lidar profile at OHP detected a layer of high ozone concentration during the night from 4 to 5 December, peaking around $445 \mathrm{~K}$ [Godin et al., 2002], which indicates the presence of air of polar origin above the lidar station. Due to the subsidence in the polar vortex and in absence of chemical destruction, as it is the case at the beginning of the winter, the ozone mixing ratio in the lower stratosphere is higher in the polar vortex than outside below the altitude of maximum mixing ratio (about $550 \mathrm{~K}$ ). Godin et al. [2002] present a statistical study showing the good correlation between the detection of polar ozone laminae by the OHP ozone lidar and the passage of polar filaments simulated by MIMOSA. Figure 1 shows the filament simulated by MIMOSA at $460 \mathrm{~K}$ for 5 December, 0000 UT, and Figure 2 shows its latitude-potential temperature cross section at the longitude of the station. At OHP, the level of maximum mixing ratio is slightly shifted from $445 \mathrm{~K}$ in the lidar profile to $460 \mathrm{~K}$ in MIMOSA. Taking into account the large slope in the filament level with latitude, this can be explained by an error of less than $1^{\circ}$ in latitude in the prediction by MIMOSA of the filament location. The $1^{\circ}$ error is in good agreement with the estimation of the accuracy on the filament location simulated with contour advection codes by comparison with airborne ozone lidar 
Table 1. Sensitivity Tests Made With Several Runs of MIMOSA

\begin{tabular}{|c|c|c|c|c|c|c|c|c|c|}
\hline Run & $\begin{array}{l}\text { Meteorological } \\
\text { Resolution }\end{array}$ & $\begin{array}{l}\text { Meteorological } \\
\text { Time Step }\end{array}$ & $\begin{array}{c}\text { MIMOSA. } \\
\text { Resolution, } \\
\text { km }\end{array}$ & $\begin{array}{l}\text { Relaxation } \\
\text { Time, Days }\end{array}$ & $\begin{array}{c}\text { Time } \\
\text { Interpolation }\end{array}$ & $\begin{array}{c}\text { Parallel } \\
\text { Distance, } \\
\mathrm{km}^{\mathrm{a}}\end{array}$ & $\begin{array}{l}\text { Perpendicular } \\
\text { Distance, } \mathrm{km}^{\mathrm{b}}\end{array}$ & $\begin{array}{l}\text { Correlation/ } \\
\text { Reference }^{c}\end{array}$ & Characteristics \\
\hline 1 & 1.125 & 6 & 37 & 10 & no & 0 & 0 & 1.000 & reference \\
\hline 2 & 1.125 & 6 & 37 & 10 & yes & 17 & 7 & 0.998 & time interpolation. \\
\hline 3 & 1.125 & 12 & 37 & 10 & no & 250 & 70 & 0.915 & $12 \mathrm{~h}$ meteorological data \\
\hline 4 & 1.125 & 12 & 37 & 10 & yes & 260 & 75 & 0.915 & $12 \mathrm{~h}$ met + time interp. \\
\hline 5 & 1.125 & 24 & 37 & 10 & no & 350 & 130 & 0.889 & $24 \mathrm{~h}$ meteorological data \\
\hline 6 & 1.125 & 24 & 37 & 10 & yes & 280 & 60 & 0.895 & $24 \mathrm{~h}$ met. + time interp. \\
\hline 7 & 1.125 & 6 & 18.5 & 10 & no & 7 & 3 & 0.999 & $18.5 \mathrm{~km}$ horiz. Resol \\
\hline 8 & 1.125 & 6 & 37 & 5 & no & 35 & 20 & 0.985 & 5 days relaxation \\
\hline 9 & 1.125 & 6 & 37 & 20 & no & 20 & 10 & 0.984 & 20 days relaxation \\
\hline 10 & 2.25 & 6 & 37 & 10 & no & 90 & 10 & 0.984 & $2.25^{\circ}$ met. resol. \\
\hline 11 & 1.125 & 6 & 37 & 10 & no & 295 & 95 & 0.947 & wind error $1 \mathrm{~m} / \mathrm{s} / /$ \\
\hline 12 & 1.125 & 6 & 37 & 10 & no & 160 & 80 & 0.966 & wind error $0.2 \mathrm{~m} / \mathrm{s}+$ \\
\hline
\end{tabular}

${ }^{\text {a }}$ RMS displacement of APV contours compared to the reference run in the direction parallel to contours.

${ }^{\mathrm{b}} \mathrm{RMS}$ displacement in the direction perpendicular to APV contours.

${ }^{\mathrm{c}}$ Correlation coefficient between APV values in the current run and in the reference run.

observations [Flentje et al., 2000; Heese et al., 2001]. In order to confirm this estimation, we performed a sensitivity study on the accuracy of the results MIMOSA with a series of runs of the model in which one or two parameters were changed.

[14] For this study, the period from 2 to 6 December 1997, corresponding to the development of the large filament observed at OHP, was chosen as the reference period and the zone delimited by $40^{\circ} \mathrm{N}, 55^{\circ} \mathrm{N}, 30^{\circ} \mathrm{W}$ and $30^{\circ} \mathrm{E}$ was selected to evaluate the results. Table 1 gives the list of runs with the summary of their characteristics. Run1 is taken as a reference for the comparison with other. Run1 is made using 6 hours, $1.125^{\circ}$ ECMWF data at $475 \mathrm{~K}$ without time interpolation of the wind field. Every 6 hours and for each run from 2 to 12, the APV field is shifted in the main direction of APV contour lines and perpendicular to these contour lines until the highest correlation coefficient with the APV field in the reference run is found. In run 2, the wind field is linearly interpolated in time. The effect in the location of APV structures is very small. In runs 3 and 4, ECMWF data are taken every 12 hours. This introduces an error in the position of APV, defined as the RMS displacement compared to the position in the reference run, of 250 $\mathrm{km}$ parallel to APV contours and $70-75 \mathrm{~km}$ perpendicular to contours. We have to keep in mind that the error parallel to contours is not very inconvenient because it does not correspond to an error in APV value for a given location. We will concentrate on the error perpendicular to contours. In runs 5 and 6, ECMWF data are only taken every 24 hours. The perpendicular error is $130 \mathrm{~km}$ without time interpolation but it is decreased down to $60 \mathrm{~km}$ with time interpolation. Runs 8 and 9 are made respectively with a relaxation towards the large-scale component of ECMWF PV field with a time constant of respectively 5 and 20 days instead of 10 days in the reference run. The effect on the location of filaments is quite small (10 to $20 \mathrm{~km})$. In run 10 , the resolution of ECMWF data is decreased by a factor of 2 with a small impact on the location of APV structures. In run 11 and 12, a constant bias of $1 \mathrm{~ms}^{-1}$ along wind direction and $0.2 \mathrm{~ms}^{-1}$ perpendicular to wind direction is assumed in the ECMWF wind, in order to mimic the results of Knudsen et al. [2001], who found an average random error on calculated trajectories of Infra-Red Montgolfier balloons, flown in the Arctic vortex in 1997 and 1999, of
500 to $1000 \mathrm{~km}$ along the trajectory and less than $200 \mathrm{~km}$ cross-trajectory after 10 days of flight. The resulting errors are respectively 95 and $80 \mathrm{~km}$ in the location of APV filaments.

\section{Effective Diffusivity}

\subsection{Determination of Effective Diffusivity}

[15] If we assume that diabatic processes can be neglected, the 2-D distribution of a tracer on an isentropic surface is controlled by the horizontal motions on this surface. Following Nakamura [1996], it is possible to define an area coordinate system where $A(q, t)$ represents the area of tracer concentration greater than $q$ at time $t$. In this coordinate system, the evolution of the tracer distribution $q(A, t)$ is controlled by the diffusion across tracer contour lines and, if we assume a constant local coefficient of diffusion $\mathrm{k}$, it is governed by a diffusion equation:

$$
\frac{d q}{d t}=k \frac{d}{d A}\left[L_{e}^{2} \frac{d q}{d A}\right]
$$

where $L_{e}$ is the equivalent length of the tracer contour defined by [Nakamura, 1996]:

$$
L_{e}^{2}(A, t)=\frac{\partial}{\partial A} \int_{A} \int_{(q)}|\nabla q|^{2} d A /\left(\frac{\partial q}{\partial A}\right)^{2} .
$$

[16] It can be easily shown that $L_{e}$ is always longer than the actual length of the tracer contour [Haynes and Shuckburgh, 2000a]. The two lengths are equal only if the gradient of tracer is constant along the contour line. Using this formulation, the effective diffusivity, i.e., the diffusivity to be applied in the diffusion equation written in equivalent latitude,$\Phi_{e}$ is related to the local diffusivity by:

$$
k_{e f f}=k \frac{r^{2} L_{e}^{2}}{\left(2 \pi r \cos \left(\phi_{e}\right)^{2}\right)} .
$$

[17] It means that when contour lines are elongated, for instance due to the formation of filaments, the effective 

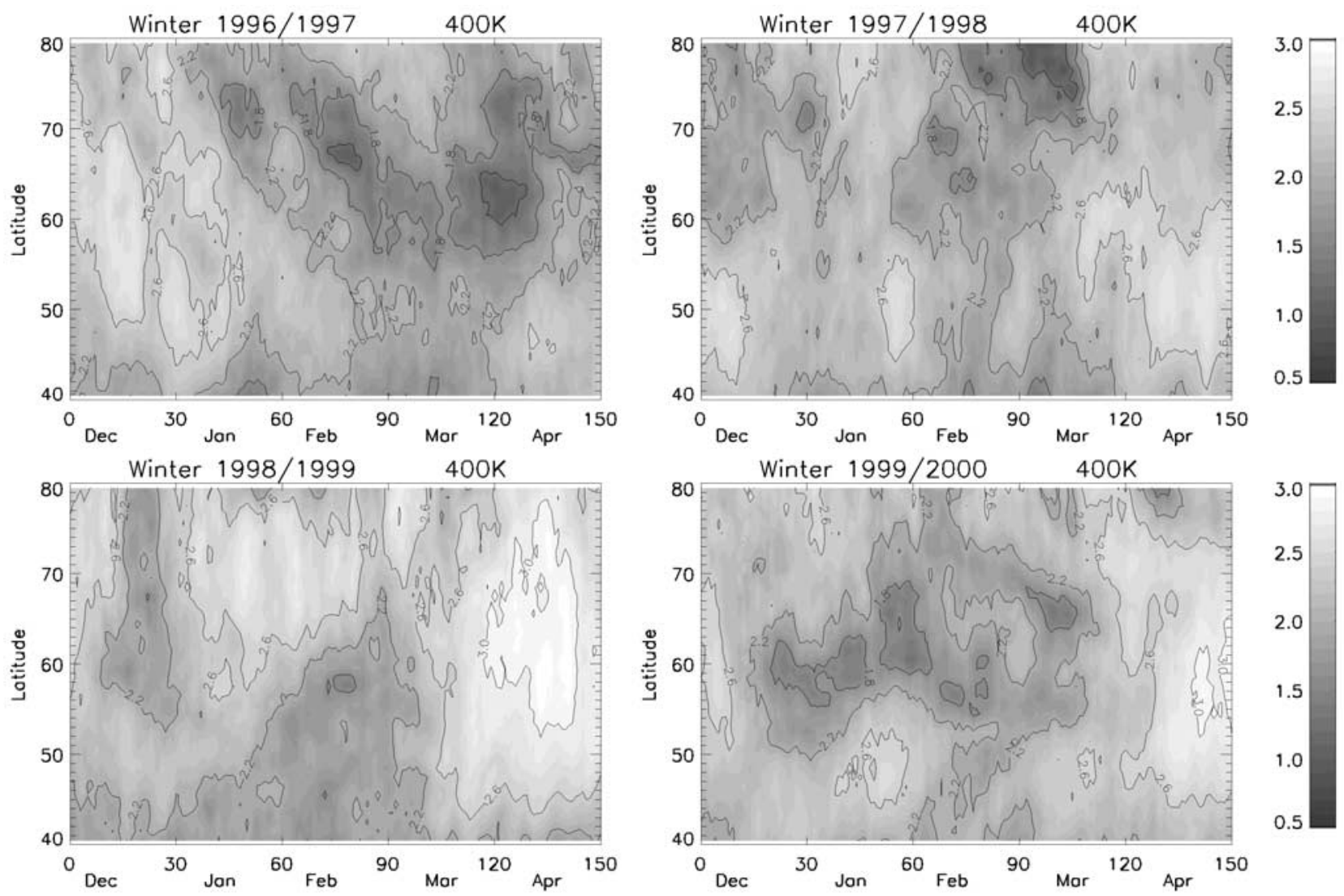

Figure 3. Effective diffusivity at $400 \mathrm{~K}$ for the four winters from 1996/1997 to $1999 / 2000$ using MIMOSA advected PV maps. A logarithmic scale base 10 is used. A value 0 corresponds to the effective diffusivity equal to the local diffusivity. A value 3 corresponds to the effective diffusivity 1000 times greater.

diffusivity is enhanced proportionally to the square of the filaments length. Using the definition of the effective diffusivity, the diffusion equation for the tracer distribution is expressed [Haynes and Shuckburgh, 2000a]:

$$
\frac{\partial C\left(\phi_{e}, t\right)}{\partial t}=\frac{1}{r^{2} \cos \left(\phi_{e}\right)} \frac{\partial}{\partial \phi_{e}}\left[k_{e f f}\left(\phi_{e}, t\right) \cos \left(\phi_{e}\right) \frac{\partial C\left(\phi_{e}, t\right)}{\partial \phi_{e}}\right] .
$$

[18] The effective diffusivity diagnostic has been applied by Haynes and Shuckburgh [2000a, 2000b] to a tracer advected by observed winds in the stratosphere $(400-850$ $\mathrm{K})$ and in the upper troposphere lower stratosphere (300$450 \mathrm{~K})$. They found that effective diffusivity was a very efficient tool to identify barriers to transport and mixing regions, and to follow their seasonal evolution. In the second paper, they showed also examples of effective diffusivity applied to potential vorticity field calculated directly from meteorological data. If we consider the mixing of tracers in the lower-middle stratosphere, we may expect that APV fields obtained using a high-resolution transport models are more representative of the true tracer fields than PV fields computed from meteorological data, especially at smaller scales where the PV is not fully conserved and where the mixing takes place. It is then anticipated that the effective diffusivity diagnostic should work better to estimate the mixing of tracers with high-resolution APV fields than with PV fields derived from meteorological analyses.
[19] In order to study the permeability of the vortex edge, the effective diffusivity has been computed at five isentropic levels, 400, 435, 475, 550, and $675 \mathrm{~K}$ for the four winters $1996 / 1997$ to $1999 / 2000$. Daily maps of APV have been computed at a resolution of $1 / 3^{\text {rd }}$ of degree in latitude and longitude from $30^{\circ} \mathrm{N}$ to $90^{\circ} \mathrm{N}$ and from 1 December to 30 April. The model was initialized on 1 November in order to have already a good representation of the filamentary structure at the beginning of the study period. For each grid point, the equivalent latitude is determined and rounded to the nearest latitude degree and APV gradients are computed. Then, the equivalent length is computed by summing the expression under the integral on all grid points with the same equivalent latitude. For consistency, the local diffusivity assumed for the computation of the effective diffusivity is the same than the numerical diffusivity estimated in the corresponding MIMOSA run, $1350 \mathrm{~m}^{2} \mathrm{~s}^{-1}$ in the standard case.

\subsection{Evolution of the Effective Diffusivity During Winters 1996/1997 and 1999/2000}

[20] The stratospheric meteorology was very different during the four winters. Winters 1996/1997 and 1999/2000 where characterized by cold temperatures and a stable vortex. However, the temporal evolution of the stratospheric temperature was not the same during these two winters. In 1996/97, the vortex was relatively warm in November and December and cold temperatures were observed very late until mid- 
April [Naujokat, 2000]. On the contrary, in 1999/2000, cold temperatures started as early as late November but a stratospheric warming occurred in March [Manney and Sabutis, 2000]. Figures 3 to 7 present the evolution of the effective diffusivity during the four winters at levels $400,435,475,550$, and $675 \mathrm{~K}$. If we consider first the $475 \mathrm{~K}$ level (Figure 5), the two cold winters are characterized by very low values of effective diffusivity in the latitude band $58^{\circ} \mathrm{N}$ and $72^{\circ} \mathrm{N}$. However, the period when these low values were reached is shifted by at least one month, from early January to mid March in 1996/1997 and from early December to early March in 1999/2000. This time evolution is in very good agreement with the evolution the temperature in the vortex. This is not surprising because both the temperature in the vortex and the effective diffusivity are increased when planetary waves break and a stratospheric warming occurs. The two other winters, $1997 / 1998$ and $1998 / 1999$, are characterized by a warm and dynamically disturbed vortex. In 1997/1998 a strong minor warming occurred in January and after that the vortex reformed but with a reduced size and the region of low effective diffusivity is limited southwards to $65^{\circ} \mathrm{N}$. In 1998/ 1999 a major warming occurred in late December and the region of low effective diffusivity disappeared in January. It formed again in February but it was destroyed by the final warming in March. At $435 \mathrm{~K}$ (Figure 4), the evolution is in general very similar but with larger values of effective diffusivity, indicating that the permeability of the vortex edge is stronger. In January 2000, the area of low values was limited northward to $66^{\circ} \mathrm{N}$ instead of $72^{\circ} \mathrm{N}$ at $475 \mathrm{~K}$ and more mixing took place inside the vortex. At 550 and $675 \mathrm{~K}$ (Figures 6 and 7), lowest values were observed, showing a strongest isolation of the vortex. This is particularly true at the beginning of the winter. For instance, in 1996-1997, the vortex isolation started around mid-December at $675 \mathrm{~K}$, at least one month earlier than at $475 \mathrm{~K}$. At $400 \mathrm{~K}$ (Figure 3) the vortex is much less isolated and a significant mixing between high and middle latitudes takes place almost all the time, except in March-April 1997 where the isolation of the vortex extended down to this level. This is probably related to the very long duration of the stable vortex which allowed the diabatic descent of the bottom of the vortex down to $400 \mathrm{~K}$.

[21] For winters 1996-1997 and 1997-1998, it is possible to compare our results on with those of Haynes and Shuckburgh [2000a] who presented in Figure 6 the evolution of effective diffusivity at $400,450,550$, and $850 \mathrm{~K}$ from December 1996 to May 1998. A direct comparison can be made at 400 and $550 \mathrm{~K}$ and their $450 \mathrm{~K}$ level can be compared to our 435 and $475 \mathrm{~K}$ levels. The results on the temporal evolution of the effective diffusivity are in good agreement, even for some small details. At 450 and $550 \mathrm{~K}$ they found the same difference between winter 1996-1997 with a strong isolation of the vortex and winter 1997-1998 with a less isolated and smaller vortex. They found that the lower limit of the polar vortex barrier occurs somewhere between 400 and $450 \mathrm{~K}$, except in March-April 1997 where the polar barrier extends down to $400 \mathrm{~K}$, in agreement with our results. The use of a high-resolution advection model to compute the effective diffusivity allows us to have a much smaller local diffusivity, in the order of $10^{3} \mathrm{~m}^{2} \mathrm{~s}^{-1}$ than when a conventional spectral model is used for the advection of tracer as in Haynes and Shuckburgh [2000a, 2000b] where the local diffusivity is 2 order of magnitude larger, in the order of $10^{5} \mathrm{~m}^{2} \mathrm{~s}^{-1}$, for a T85 spectral resolution of the model. In our study, the contrast between the minimum of effective diffusivity in the polar barrier and the maximum in the surf zone can be as high as 300 , when it is limited to about 20 in their study.

\section{Quantification of the Transport From the Polar Vortex to Midlatitude}

[22] The use of effective diffusivity allows us to quantify the horizontal transport on an isentropic surface in a 1-D coordinate system defined by the equivalent latitude $\Phi$ e. In this coordinate system, the temporal evolution of a tracer of which the mixing ratio is depending only on $\Phi e$ is controlled by the diffusion equation (4). In order to quantify the transport from the polar vortex to midlatitude occurring during each winter, a polar tracer was initialized to 1 on 1 January of each year, inside the polar vortex, defined as $\Phi$ e $>65^{\circ} \mathrm{N}$, and to 0 outside. The equivalent latitude of the vortex edge was estimated using the Nash et al. [1995] method on MIMOSA-generated APV fields when the vortex is well formed. To facilitate comparisons, the same limit is taken for each year even if they exist an interannual variability on the position of the vortex edge. The starting date was chosen in order to have a polar vortex already well defined in most of the cases. The evolution of the polar tracer was computed for the four winters and at the four isentropic levels $435,475,550$, and $675 \mathrm{~K}$. The $400 \mathrm{~K}$ level is not considered because at this level the polar vortex is in general not clearly defined. Three regions are considered according to the average equivalent latitude of the vortex edge, inside vortex $\left(\Phi \mathrm{e}>65^{\circ} \mathrm{N}\right)$, vortex edge $\left(60^{\circ} \mathrm{N}<\Phi \mathrm{e}<\right.$ $\left.65^{\circ} \mathrm{N}\right)$ and outside vortex $\left(\Phi \mathrm{e}<60^{\circ} \mathrm{N}\right)$. The vertical motion of air across isentropic surfaces due to diabatic effects is not taken into account in this study. An air parcel inside the vortex experiences a diabatic descent which increases with height and is maximum at the beginning of the winter. Using the radiative code of SLIMCAT model, Rex et al. [2002] estimated the evolution of the potential temperature of an air parcel in winter 1999-2000. They found that polar air parcels at 400,435 , and $475 \mathrm{~K}$ on 31 March were respectively at 415,460 , and $550 \mathrm{~K}$ on 1 January. The transport computed at a given isentropic level will not concern the same polar air mass at the beginning and at the end of the winter. Therefore our results concerning the cumulative transport during the winter will have to be interpreted with caution. However, we think that they give a good estimation of the transport taking place across the vortex edge and a clear description of its altitude and temporal dependence.

[23] The appropriate value of the diffusivity $k$ to be used to represent the real atmosphere is quite uncertain. In order to test the sensitivity of the results to the assumed value for $k$, two additional runs of the advection model were made for winter 1999-2000 at $475 \mathrm{~K}$, one with a higher resolution $(28 \mathrm{~km}$ instead of $37 \mathrm{~km}$ in the standard case) corresponding to a lower numerical diffusivity $\left(760 \mathrm{~m}^{2} \mathrm{~s}^{-1}\right.$ instead of $1350 \mathrm{~m}^{2} \mathrm{~s}^{-1}$ ) and one with a coarser resolution $(56 \mathrm{~km})$ and higher numerical diffusivity $\left(3040 \mathrm{~m}^{2} \mathrm{~s}^{-1}\right)$. For consistency, the value of the diffusivity used for the estimation of the meridional transport in equation (4) is 
SOL $32-8$ HAUCHECORNE ET AL.: TRANSPORT OF CONSTITUENTS IN THE STRATOSPHERE
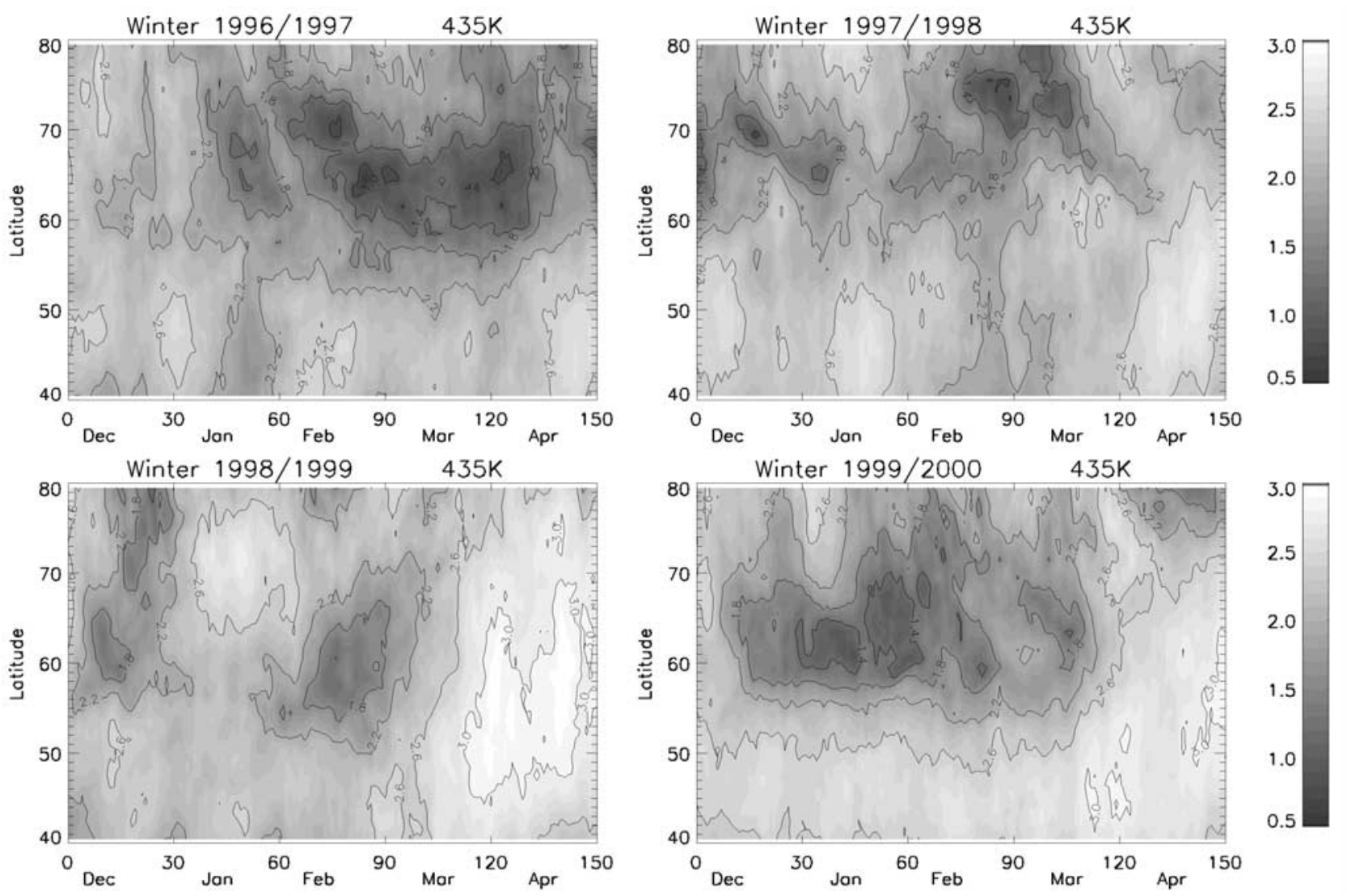

Figure 4. As in Figure 3 but for $435 \mathrm{~K}$.
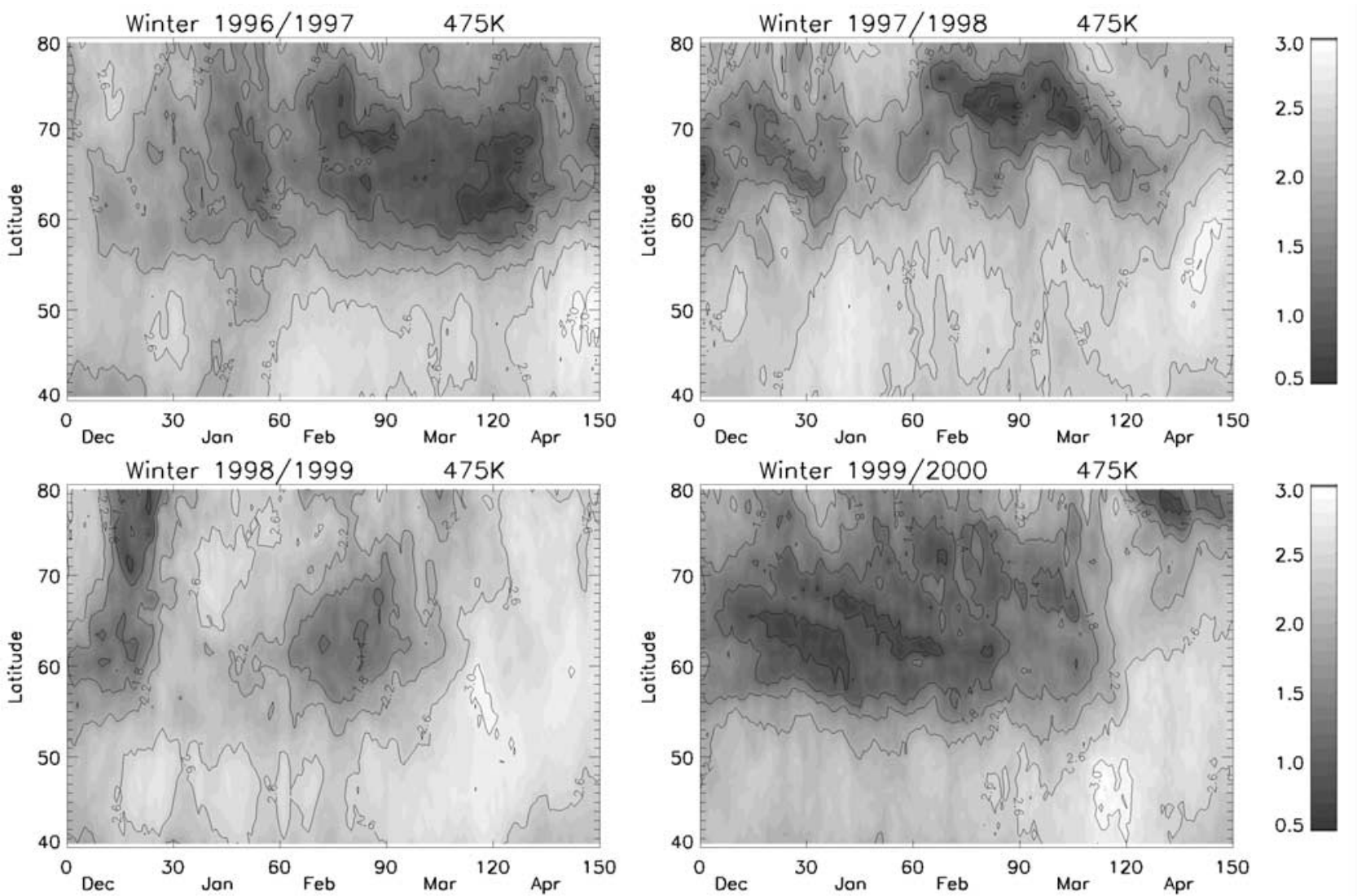

Figure 5. As in Figure 3 but for $475 \mathrm{~K}$. 

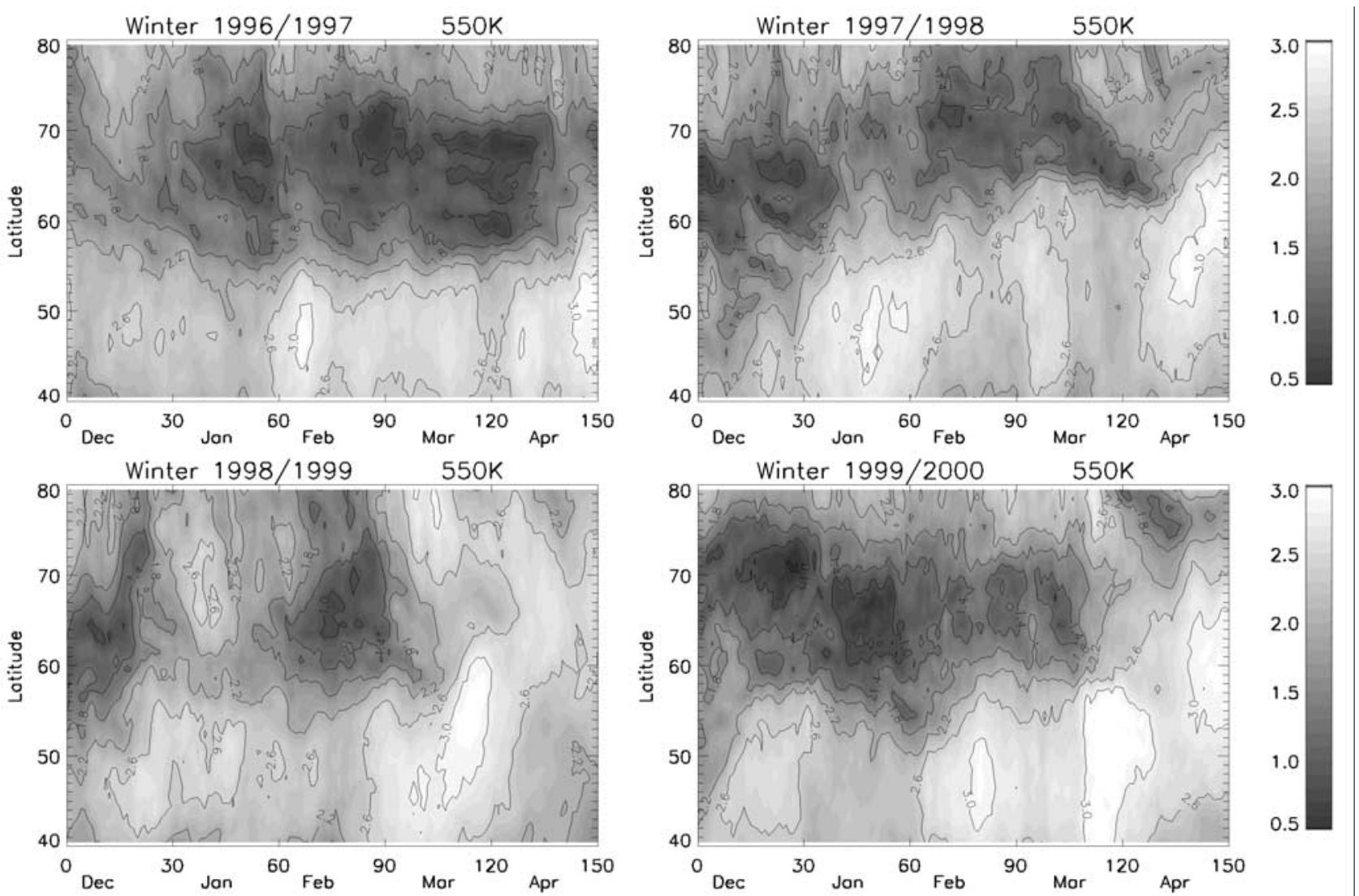

Figure 6. As in Figure 3 but for $550 \mathrm{~K}$.
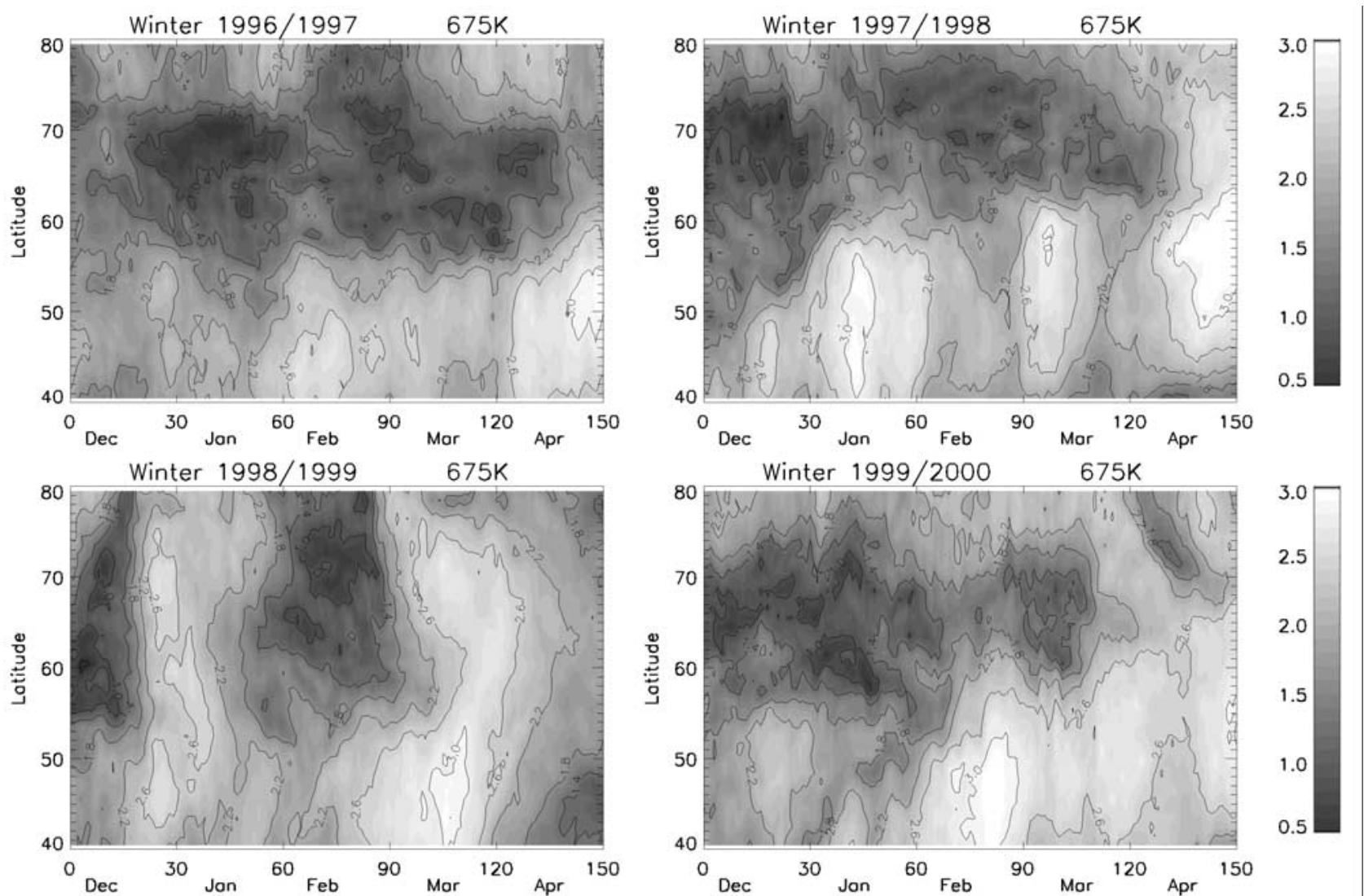

Figure 7. As in Figure 3 but for $675 \mathrm{~K}$. 


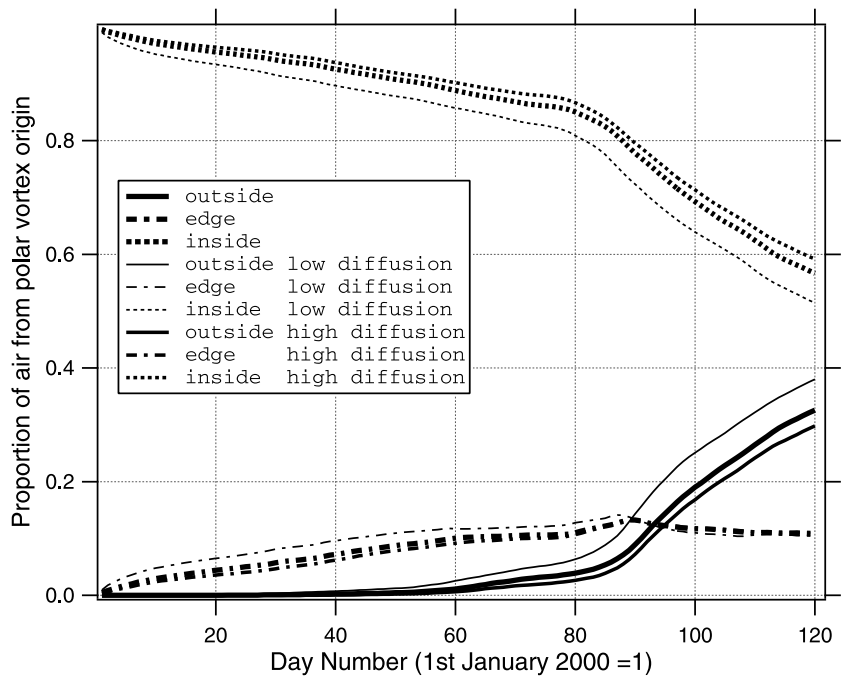

Figure 8. Evolution during winter 2000 of the proportion of air of polar vortex origin (equivalent latitude $>65^{\circ} \mathrm{N}$ ) on 1 January 2000 in three equivalent latitude bands, equivalent latitude $>65^{\circ} \mathrm{N}$ (inside), $60^{\circ} \mathrm{N}>$ equivalent latitude $>65^{\circ} \mathrm{N}$ (edge) and equivalent latitude $<60^{\circ} \mathrm{N}$.

taken equal to the corresponding numerical diffusivity in MIMOSA code. The evolution of the proportion of polar tracer in the three regions (Figure 8) is not very different between the three runs. The cumulative transport of air during the winter is only increased by less than $30 \%$, from $30 \%$ of polar vortex area in the low diffusivity case to $38 \%$ in the high diffusivity case, when the local diffusivity is increased by a factor of 4 . In the same time, the proportion of polar tracer staying in the vortex is decreased from 50 to $42 \%$. This result may seem surprising but can be explained by the fact that, when the local diffusivity $k$ increases, the equivalent length of tracer contour lines $\mathrm{L}_{\mathrm{e}}$ decreases and the two terms in equation (3) compensate partially. The deformation of the vortex edge by breaking of large-scale Rossby waves brings filaments or bubbles of polar vortex air to midlatitude. The local diffusivity controls the rate at which the polar air is irreversibly mixed with the surrounding midlatitude air but the mixing will finally occur even if the local diffusivity is very small. Therefore the estimation of the meridional transport is not too sensitive to the uncertainty in the local diffusivity.

[24] The evolution of the proportion of polar tracer at midlatitude during the four winters and at the five isentropic levels is presented in Figure 9. In all cases the transport is maximum at the lower level $435 \mathrm{~K}$, where the isolation of the polar vortex is weaker (see section 4) and decreases with height up to $550 \mathrm{~K}$. At $675 \mathrm{~K}$ the transport is stronger or weaker than at $550 \mathrm{~K}$ depending on the year and on the period in the winter. The interannual variability observed in the effective diffusivity is also visible in the meridional transport. During periods with a very cold and isolated vortex, from January to April 1997 and from January to
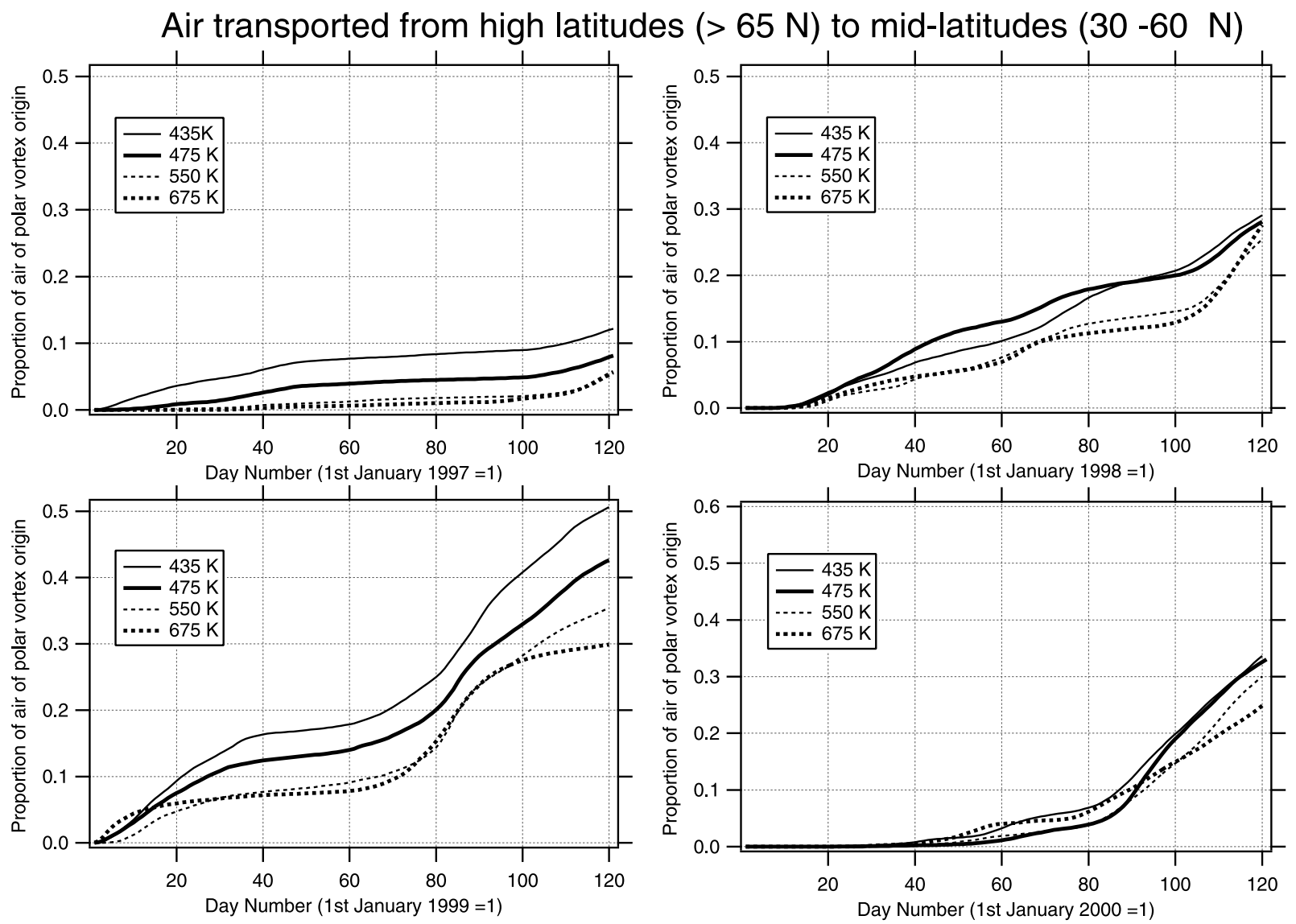

Figure 9. Proportion of air outside vortex (equivalent latitude $<60^{\circ} \mathrm{N}$ ) from polar vortex origin on 1 January of the given winter at four isentropic levels: 435,475 , 550, and $675 \mathrm{~K}$. 
March 2000, the transport is very weak. During a stratospheric warming event, like in March 1999, or during the final break up of the vortex, as in April 2000, 20 to 30\% of the polar tracer is transported to midlatitude at all levels. When the vortex is relatively disturbed, as in 1998, a significant amount of the polar tracer is also transported at all levels all along the winter. The cumulative transport from 1 January to the end of April is very variable from one winter to another. It is maximum during the very warm and disturbed winter 1999 (between $30 \%$ at 550 and $675 \mathrm{~K}$ and $50 \%$ at $435 \mathrm{~K}$ ) and minimum during the very cold winter 1997 (between 5\% at $675 \mathrm{~K}$ and $12 \%$ at $435 \mathrm{~K}$ ). The large interannual variability in the transport of activated polar air to midlatitudes was shown by Norton and Chipperfield [1995] using an off-line chemistry transport model and a contour advection code. On the $475 \mathrm{~K}$ isentropic surface, they found that $10 \%$ of the total vortex mass was transported in 1991-1992 and 50\% in 1993-1994. Knudsen and Gross [2000] used reverse domain filling trajectories to estimate the dilution of the polar vortex to midlatitude in April-May 1997. They found that $40 \%$ of the observed ozone decline at midlatitude can be explained by the dilution of ozone-depleted polar air. If we consider that the transport was very weak in April (Figure 9), most of the dilution should have occurred in May during the final break up of the vortex. This is consistent with Figure 1 of their paper showing the temporal development of the dilution.

\section{Summary}

[25] A high-resolution advection model MIMOSA has been developed in the frame of the METRO-THESEO project for analysis and forecast of polar filamentation. In early December 1997, a large polar filament developed above Europe and North Atlantic. It allowed us to evaluate the accuracy in the location of PV filaments simulated by MIMOSA as a function of several parameters. In all cases but one, the one with low time resolution in the wind data and no time interpolation, the location of filaments was estimated with an accuracy in the order or better than 100 $\mathrm{km}$, in good agreement with comparisons made between airborne lidar observations and contour advection simulations [Flentje et al., 2000; Heese et al., 2001]. The strongest error in the location of filament is found when we assume a constant bias in the speed of ECMWF advecting wind.

[26] A second-order interpolation scheme has been developed to limit the numerical horizontal diffusivity induced by regridding of the APV field to values in the order of $10^{3}$ $\mathrm{m}^{2} \mathrm{~s}^{-1}$, comparable to the estimation of the local horizontal diffusivity from high-resolution aircraft data [Waugh et al., 1997; Balluch and Haynes, 1997]. This allowed us to use MIMOSA model to estimate the effective diffusivity as a function of the equivalent latitude and the transport of polar air to midlatitude during the four winters 1996-1997 to $1999-2000$ at five isentropic levels from 400 to $675 \mathrm{~K}$. The effective diffusivity diagnostic is particularly well adapted to high-resolution advected PV fields. The contrast between dynamical barrier (polar edge) and mixing regions (midlatitude surf zone) is enhanced by the use of a highresolution advection model.

[27] A large year to year variability is found in the effective diffusivity around the polar edge and in the transport of air from the polar vortex to midlatitudes. The effective diffusivity decreases with altitude between 400 and $550 \mathrm{~K}$ and is nearly constant between 550 and $675 \mathrm{~K}$. At $400 \mathrm{~K}$, the polar barrier is poorly defined and the mixing between polar and midlatitude air occurs almost all the time. At higher levels, most of the transport occurs during stratospheric warmings periods when the vortex breaks up (see also Waugh et al. [1994] for an estimation of the transport during Rossby wave breaking). When the vortex is cold and stable, condition favorable to the formation of polar stratospheric clouds and chlorine activation, the transport from the polar vortex to midlatitudes is very weak. This result suggests that the irreversible midwinter transport of ozone-depleted air to midlatitudes in polar filaments plays a minor role in the observed decline of ozone at midlatitude. However, this does not exclude a contribution to this decline of polar air excursion above midlatitude stations as discussed by Godin et al. [2002]. At a given isentropic level; the cumulative transport from the polar vortex to midlatitude from early January to end of April varies from $5 \%$ of the polar vortex area at $675 \mathrm{~K}$ in 1997 , when the vortex was very stable, to $50 \%$ at $435 \mathrm{~K}$ during the very disturbed winter 1999 . It is interesting to note that the estimation of the transport using the effective diffusivity is only slightly sensitive to the value of the assumed for the local diffusivity. An increase of the local diffusivity by a factor 4 induces an increase of the exportation of polar air by less than $30 \%$. This can be explained by the fact that, when some filaments or bubbles of polar vortex air are transported to midlatitude by breaking of large-scale Rossby waves, they will be finally mixed with the surrounding midlatitude air even if the local diffusivity is very small. Therefore the estimation of the meridional transport is quite accurate in spite of the large uncertainty on the local diffusivity in the real atmosphere.

\section{Appendix A: Regridding Scheme and Numerical Diffusion}

[28] Due to the finite resolution of the advection model, the process of regridding induces some numerical diffusion. Two scheme of regridding were developed in MIMOSA. The first one is a bilinear interpolation. A grid point $\left(x_{i, j}, y_{i, j}\right)$ of the orthogonal grid at which we want to interpolate the advected PV field is included inside a quadrangle on the advected grid, resulting from the advection of an elementary square of the grid, delimited by the four advected grid points:

$\left(x_{i^{\prime}, j^{\prime}}^{\prime}, y_{i^{\prime}, j^{\prime}}^{\prime}\right),\left(x_{i^{\prime}+1, j^{\prime}}^{\prime}, y_{i^{\prime}+1, j^{\prime}}^{\prime}\right),\left(x_{i^{\prime}+1, j^{\prime}+1}^{\prime}, y_{i^{\prime}+1, j^{\prime}+1}^{\prime}\right)$ and $\left(x_{i^{\prime}, j^{\prime}+1}^{\prime}, y_{i^{\prime}, j^{\prime}+1}^{\prime}\right)$.

[29] Using an iteration algorithm, it is possible to determine the reduced coordinates $(X, Y)$ of the grid point $\left(x_{i, j}, y_{i, j}\right)$ in the advected quadrangle with $0 \leq x \leq 1$ and $0 \leq y \leq 1$ such as:

$$
\begin{aligned}
x_{i, j}= & (1-X)(1-Y) x_{i^{\prime}, j^{\prime}}^{\prime}+X(1-Y) x_{i^{\prime}+1, j^{\prime}}^{\prime} \\
& +(1-X) Y x_{i^{\prime}, j^{\prime}+1}^{\prime}+X Y x_{i^{\prime}+1, j^{\prime}+1}^{\prime}
\end{aligned}
$$$$
y_{i, j}=(1-X)(1-Y) y_{i^{\prime}, j^{\prime}}^{\prime}+X(1-Y) y_{i^{\prime}+1, j^{\prime}}^{\prime}
$$$$
+(1-X) Y y_{i^{\prime}, j^{\prime}+1}^{\prime}+X Y y_{i^{\prime}+1, j^{\prime}+1}^{\prime},
$$ 
and the regridded value of an advected quantity Q (for instance the advected PV) is given by:

$$
\begin{aligned}
Q_{i, j}= & (1-X)(1-Y) Q_{i^{\prime}, j^{\prime}}^{\prime}+X(1-Y) Q_{i^{\prime}+1, j^{\prime}}^{\prime} \\
& +(1-X) Q y_{i^{\prime}, j^{\prime}+1}^{\prime}+X Y Q_{i^{\prime}+1, j^{\prime}+1}^{\prime} .
\end{aligned}
$$

[30] The numerical diffusivity induced by this scheme can be estimated by looking at the diffusion of a Dirac function during the regridding process. For simplification, the demonstration is limited to the $x$ dimension. Equation (A2) is written:

$$
Q_{i}=(1-X) Q_{i^{\prime}}^{\prime}+X Q_{i^{\prime}+1}^{\prime}
$$

The Dirac function is defined as:

$$
\begin{gathered}
Q_{i 0}^{\prime}=1, Q_{i}^{\prime}=0 \text { for } i \neq i_{0} \\
\frac{x_{i 0}^{\prime}-x_{i 1}}{x_{i 1+1}-x_{i 1}}=X .
\end{gathered}
$$

[31] The second-order momentum $\mathrm{M}_{2}$ of the perturbation in the $x$ direction is equal to 0 before regridding and takes a value after regridding equal to:

$$
M_{2}=\left[X^{2}(1-X)+(1-X)^{2} X\right] \Delta x^{2},
$$

where $\Delta \mathrm{x}$ is the grid size. If we average over all possible $x$ values in the domain $0 \leq x \leq 1$ and $0 \leq y \leq 1$, we obtain

$$
\overline{M_{2}}=\int_{0}^{1}\left[X^{2}(1-X)+(1-X)^{2} X\right] d X \Delta x^{2}=\frac{\Delta x^{2}}{6} .
$$

[32] We consider now a normalized perturbation $\mathrm{p}(\mathrm{x})$ in the $x$ direction centered at 0 at which we apply the diffusion equation with a constant diffusivity $\mathrm{k}$. The function $\mathrm{p}(\mathrm{x})$ is defined as:

$$
\begin{gathered}
p(x), \frac{d p}{d x}, \frac{d^{2} p}{d x^{2}}=0 \text { for }|x| \geq x_{\max } \\
\int_{-x \max }^{\mathrm{xmax}} \mathrm{p}(\mathrm{x}) \mathrm{dx}=1, \int_{-\mathrm{x} \max }^{\mathrm{x} \max } \mathrm{xp}(\mathrm{x}) \mathrm{dx}=0
\end{gathered}
$$

The time derivative of its second-order momentum is expressed as:

$$
\begin{aligned}
\frac{d M_{2}}{d t} & =\frac{d}{d t} \int_{-x \max }^{x \max } x^{2} p(x) d x \\
& =k \int_{-x \max }^{x \max } x^{2} \frac{d^{2} p}{d x^{2}} d x=k\left[x^{2} \frac{d p}{d x}\right]_{-x \max }^{-x \max }-2 k \int_{-x \max }^{x \max } x \frac{d p}{d x} d x \\
& =k\left[x^{2} \frac{d p}{d x}\right]_{-x \max }^{-x \max }-2 k[x p(x)]_{-x \max }^{-x \max }+2 k \int_{-x \max }^{x} p(x) d x=2 k .
\end{aligned}
$$

[33] The diffusivity induced by the regridding is estimated assuming that the increase of $\overline{M_{2}}$ during a time step
$\Delta t$ between two regriddings (equation (4)) is equal to the time derivative of M2 (equation (6)) multiplied by the time step:

$$
k=D_{x x}=D_{y y}=\frac{\Delta x^{2}}{12 \Delta t}
$$

[34] This gives $D_{x x}=1320 \mathrm{~m}^{2} \mathrm{~s}^{-1}$ for $\Delta x=18.5 \mathrm{~km} \mathrm{(6}$ grid points/degree) and $D_{x x}=5280 \mathrm{~m}^{2} \mathrm{~s}^{-1}$ for $\Delta x=37 \mathrm{~km}$ (3 grid points/degree). In order to reduce the numerical diffusivity, a second-order scheme has been developed based on the conservation of the second-order momentum of the shape of a perturbation. The scheme is described only along the direction $x$ for simplification but is applied in both directions in the model. The reduction of the diffusion is obtained by computing the regridded value $Q$ as a linear combination of advected values $Q^{\prime}$ at advected grid points $x_{i^{\prime}-1}^{\prime}, x_{i^{\prime}}^{\prime}, x_{i+1^{\prime}}^{\prime}$ and $x_{i^{\prime}+2}^{\prime}$, with a small negative weight given at the external grid points:

$$
\begin{aligned}
Q_{i}= & -\frac{X(X-1)(X-2)}{6} Q_{i^{\prime}-1}^{\prime}+\frac{X(X-1)(X-2)}{6} Q_{i^{\prime}}^{\prime} \\
& -\frac{X(X-2)(X+1)}{6} Q_{i^{\prime}+1}^{\prime}+\frac{X(X-1)(X+1)}{6} Q_{i^{\prime}+2}^{\prime}
\end{aligned}
$$

with $0 \leq x \leq 1$. In the model, the interpolation is made on both directions and $Q_{i, j}$ is expressed as a summation of $Q^{\prime}$ over 16 advected grid points, each grid point being weighted by the product of a term in $x$ and a term in $Y$.

[35] Due to the finite resolution of the model, the numerical diffusion is not totally suppressed. In order to estimate the residual diffusivity, 1-D Fourier transform spectra of APV fields have been made in $x$ and $y$ directions and the mean power spectral density at the smaller scale resolved by the model (horizontal wavelength $=2 \Delta x$ ) has been computed for both advection schemes at various horizontal resolutions. It has been found that the numerical diffusivity using the second-order scheme and $\Delta x=37 \mathrm{~km}$ is about $1350 \mathrm{~m}^{2} \mathrm{~s}^{-1}$, almost equivalent to the numerical diffusivity using the bilinear interpolation and $\Delta x=18.5 \mathrm{~km}$.

[36] Acknowledgments. Thanks to ECMWF and NILU for providing meteorological data. This work has been supported by European Commission, Environment and Climate Programme.

\section{References}

Balluch, M. G., and P. H. Haynes, Quantification of lower stratospheric mixing processes using aircraft data, J. Geophys. Res, 102, 23,48723,504, 1997.

Edouard, S., B. Legras, F. Lefèvre, and R. Eymard, The effect of smallscale inhomogeneities on ozone depletion in the Arctic, Nature, 384, 444-447, 1996.

Flentje, H., W. Renger, and W. Wirth, Comparison of airborne lidar measurements with contour advection simulations, J. Geophys. Res, 105, $15,417-15,437,2000$.

Godin, S., M. Marchand, and A. Hauchecorne, Influence of Artic polar ozone depletion on the lower stratosperic ozone amounts at Haute-Provence Observatory $\left(44^{\circ} \mathrm{N}, 60 \mathrm{E}\right)$, J. Geophys. Res, 107(20), 10.1029/ 2001JD000516, in press, 2002.

Haynes, P. H., and M. E. McIntyre, On the conservation and impermeability theorems for potential vorticity, J. Atmos. Sci., 47, 2021-2031, 1990.

Haynes, P., and E. Shuckburgh, Effective diffusivity as a diagnostic of atmospheric transport, 1, Stratosphere, J. Geophys. Res., 105, 22,77722,794, 2000a.

Haynes, P., and E. Shuckburgh, Effective diffusivity as a diagnostic of 
atmospheric transport, 2, Troposphere and lower stratosphere, J. Geophys. Res., 105, 22,795-22,810, 2000b.

Heese, B., S. Godin, and A. Hauchecorne, Forecast and simulation of stratospheric ozone filaments: A validation of a high-resolution PV advection model by airborne ozone lidar measurements in winter 1998 1999, J. Geophys. Res., 20,011-20,024, 2001.

Knudsen, B. M., and G. D. Carver, Accuracy of isentropic trajectories calculated for the EASOE campaign, Geophys. Res. Lett., 21, 1199$1202,1994$.

Knudsen, B. M., and J.-U. Gross, Northern midlatitude stratospheric ozone dilution in spring modeled with simulated mixing, J. Geophys. Res., 105, 6885-6890, 2000.

Knudsen, B. M., et al., Comparison of stratospheric air parcel trajectories based on different meteorological analyses, J. Geophys. Res., 106, 34153424, 2001

Lait, L. R., An alternative form for potential vorticity, J. Atmos. Sci., 51, 1754-1759, 1996.

Manney, G. L., and J. L. Sabutis, Development of the polar vortex in the 1999-2000 Arctic winter stratosphere, Geophys. Res. Lett., 27, 25892592, 2000

Manney, G. L., J. C. Bird, D. P. Donovan, T. J. Duck, J. A. Whiteway, S. R. Pal, and A. I. Carswell, Modeling ozone laminae in ground-based Arctic wintertime observations using trajectory calculations and satellite data, J. Geophys. Res., 103, 5797-5814, 1998.

Mariotti, A., M. Moustaoui, B. Legras, and H. Teitelbaum, Comparison between vertical ozone soundings and reconstructed potential vorticity maps by contour advection with surgery, J. Geophys. Res., 102, 61316142, 1997.

McIntyre, M. E., and T. N. Palmer, The surf zone in the stratosphere, J. Atmos. Terr. Phys., 9, 825-849, 1984.

Methven, J., and B. Hoskins, The advection of high-resolution tracers by low resolution winds, J. Atmos. Sci., 56, 3262-3285, 1999.

Nakamura, N., Two-dimensional mixing, edge formation and permeability diagnosed in area coordinate, J. Atmos. Sci., 53, 1524-1537, 1996.

Nash, E. R., P. A. Newman, J. E. Rosenfield, and M. E. Schoeberl, An objective determination of the polar vortex using Ertel's potential vorticity, J. Geophys. Res., 100, 25,817-25,840, 1995.

Naujokat, B., The winters 1997/98 and 1998/99 in perspective, in Proceedings of the Fifth European Symposium, Saint-Jean de Luz, France, $27^{\text {th }}$ September $-1^{\text {st }}$ October 1999, Air Pollut. Res. Rep. 73, edited by N. R. P. Harris, M. Guirlet, and G. T. Amanatidis, pp. 107-110, Eur. Comm., Geneva, 2000

Norton, W. A., and M. P. Chipperfield, Quantification of the transport of chemically activated air from the northern hemisphere polar vortex J. Geophys. Res., 100, 25,817-25,840, 1995.

Orsolini, Y. J., On the formation ozone laminae at the edge of the Arctic polar vortex, Q. J. R. Meteorol. Soc., 121, 1923-1941, 1995.

Orsolini, Y., J. Hansen, G. Hoppe, U.-P. Manney, and G. L. Fricke, Dyna- mical modelling of wintertime lidar observations in the Arctic: Ozone laminae and ozone depletion, Q. J. R. Meteorol. Soc., 123, 785-800, 1997.

Orsolini, Y. J., G. L. Manney, A. Engel, J. Ovarlez, C. Claud, and L. Coy, Layering in stratospheric profiles of long-lived trace species: Balloonborne observations and modeling, J. Geophys. Res., 103, 5815-5825, 1998.

Plumb, R. A., D. W. Waugh, R. J. Atkinson, P. A. Newman, L. R. Lait, M. R. Schoeberl, E. V. Browell, A. J. Simmons, and M. Loewenstein, Intrusions into the lower stratospheric Arctic vortex during the winter of 1991-1992, J. Geophys. Res., 99, 1089-1105, 1994

Reid, S. J., and G. Vaughan, Lamination in ozone profiles in the lower stratosphere, Q. J. R. Meteorol. Soc., 117, 825-844, 1991.

Rex, M., et al., Chemical depletion of Arctic ozone in winter 1999/2000, J. Geophys. Res., 107(20), 10.1029/2001JD000533, in press, 2002.

Searle, K. R., M. P. Chipperfield, S. Bekki, and J. A. Pyle, The impact of spatial averaging on calculated ozone loss, 1, Model experiments, J. Geophys. Res., 103, 25,397-25,408, 1998a.

Searle, K. R., M. P. Chipperfield, S. Bekki, and J. A. Pyle, The impact of spatial averaging on calculated ozone loss, 2, Theoritical analysis, J. Geophys. Res., 103, 25,409-25,416, $1998 \mathrm{~b}$.

Sparling, L. C., A. R. Douglass, and M. R. Schoeberl, An estimate of the effect of unresolved structure on modeled ozone loss from aircraft observations of ClO, Geophys. Res. Lett., 25, 305-308, 1998.

Tan, D. G. H., P. H. Haynes, A. R. MacKenzie, and J. A. Pyle, Effects of fluid-dynamical stirring on the deactivation of chlorine, J. Geophys. Res., 103, 1585-1605, 1998 .

Waugh, D. W., et al., Transport out of the lower stratosphere Arctic vortex by Rossby wave breaking, J. Geophys. Res., 99, 1071-1088, 1994.

Waugh, D. W., et al., Mixing of polar vortex air into middle latitudes as revealed by tracer-tracer scatterplots, J. Geophys. Res., 102, 13,11913,134, 1997.

Weaver, C. J., A. R. Douglass, and R. B. Rood, Lamination frequencies as a diagnostic for horizontal mixing in a 3-D transport model, J. Atmos. Sci., 57, 247-261, 2000 .

World Meteorological Organization (WMO), Scientific Assessment of Ozone Depletion, 1998, Global Ozone Res. and Monit. Proj., World Meteorol. Org., Geneva, 1999.

S. Godin, A. Hauchecorne, B. Hesse, M. Marchand, and C. Souprayen, Service d'Aéronomie du CNRS, B.P. No. 3, Verrières-le-Buisson Cedex, F-91371, France. (sophie.godin@aero.jussieu.fr; alain.hauchcorne@aerov. jussieu.fr; b.heese@gtco.de; marion.marchand@aero.jussieu.fr; claude. souprayen@aerov.jussieu.fr) 